\title{
IGUALDADE CONTRATUAL NO DIREITO BRASILEIRO: NOVA RACIONALIDADE E HERMENÊUTICA PELO PRISMA CONSTITUCIONAL
}

Jorge Renato dos Reis ${ }^{1}$
Igor Andrei Cezne

\section{RESUMO}

O estudo versa sobre a reinterpretação da igualdade material nos contratos, partindo da verificação histórica da igualdade, ligada ao racionalismo, salienta a necessidade de serem superadas idéias liberais e, portanto, descomprometidas com a realidade, porque mantenedoras do status quo. O conceito de igualdade em tal aspecto (material) depende da efetiva vulnerabilidade do contratante, a ser verificada no caso concreto, sem cair, todavia, num decisionismo ou num relativismo (afastados pela condição última de legitimação do ato estatal: a motivação da decisão judicial).

Palavras-chave: Constitucionalização do Direito Privado; contrato; igualdade.

\section{INTRODUÇÃO}

No âmbito das relações contratuais, o modelo tradicional, calcado no paradigma patrimonialista ínsito às legislações oitocentistas, vive seu ocaso. O espaço privado, protegido pelo Estado Liberal para a livre e soberana disposição de vontade dos contratantes (pacta sunt servanda), cede terreno para um modelo contratual que busca a recuperação do logos humano, centro e justificativa do sistema jurídico.

Nesse sentido, no Brasil, o verdadeiro divisor de águas ocorreu com o advento da Constituição Federal de 1988, ao erigir, como valores principais exigidos do Estado, agora considerado Estado Democrático de Direito, a dignidade humana (artigo $1^{\circ}, \mathrm{III}$ ) e o solidarismo (artigo $3^{\circ}, \mathrm{I}$ ), e, como direito fundamental, a igualdade 
material (artigo $5^{\circ}$ ). Assim, todos os setores do ordenamento (inclusive, e principalmente, aqueles tradicionais) devem passar a ser vistos pela ótica constitucionalizante.

Para interpretar as posições subjetivas em qualquer contrato, não basta a observância às normas ordinárias; é necessário estabelecer juízo de adequação aos valores e princípios incorporados pela ordem constitucional, notadamente a isonomia. Nessa nova racionalidade hermenêutica, o homem ganha outro status, pelo qual são reconhecidas as diferenças materiais, e a sua dignidade passa a ser objeto de proteção do sistema, inclusive em relação aos contratos.

A questão está em saber em que medida e de que forma os ditames constitucionais, especificamente o direito fundamental à igualdade, têm eficácia nas relações entre particulares, assegurando mobilidade ao Direito, redimensionando o valor da segurança e construindo um sistema mais sensível à realidade e aos problemas sociais. Nessa senda, o contrato deixa de ser um instrumento puro e simples de troca de riquezas, para voltar-se à promoção da dignidade humana, pressuposto da igualdade material e não meramente formal. Como conseqüência, liberta-se dos grilhões da manutenção e da reprodução acrítica da manualística tradicional sobre a matéria, debelando a docilidade do adestramento provocado por autores descomprometidos com a mudança.

Nesse contexto, o presente trabalho busca identificar a importância e as conseqüências da eficácia do princípio da igualdade material nas relações contratuais entre particulares, com suas implicações teóricas e práticas na dinâmica que ultrapassa os limites das relações de consumo, tutelando toda parte que possa ser considerada vulnerável nas circunstâncias do caso concreto.

\section{$1 \mathrm{~A}$ igualdade como direito fundamental}

O ordenamento constitucional brasileiro elenca como norma de direito fundamental o princípio da igualdade, ao dispor, no caput do seu artigo $5^{\circ}$, que "todos são iguais perante a lei, sem distinção de qualquer natureza, garantindo-se 
aos brasileiros e aos estrangeiros residentes no País a inviolabilidade do direito à vida, à liberdade, à igualdade, à segurança e à propriedade [...]". Pela normatividade dos princípios, pode-se dizer que a igualdade "confere um direito subjetivo (dimensão subjetiva), é um princípio objetivo que se projeta sobre todo o ordenamento jurídico (dimensão objetiva dos direitos fundamentais como princípios objetivos), tem aplicabilidade imediata (artigo $\left.5^{\circ} \S 1^{\circ}, \mathrm{CF}\right)[\ldots]^{\prime}$. Ademais, em razão de sua fundamentalidade, "está imune ao poder constituinte reformador (artigo 60, § $4^{\circ}$, IV, CF) e, portanto, ocupa uma posição preferente na ordem jurídica" (STEINMETZ, 2004, p. 231-232).

Numa apressada leitura, pode-se entender que o preceito seria destinado exclusivamente ao julgador. Entretanto, conforme assente na doutrina, vincula também o legislador, já que este não poderá editar normas prevendo tratamento distinto entre as pessoas, ou, pelo menos, sem uma razão constitucionalmente adequada.

Buscando concretizar essa norma de direito fundamental, doutrina e jurisprudência estabeleceram três mandamentos: (a) mandamento de tratamento igual, (b) mandamento de tratamento desigual ou diferenciado e (c) proibição de tratamento discriminatório. Segundo Wilson Steinmetz, os dois primeiros decorrem da previsão "todos são iguais perante a lei" (art. $5^{\circ}$, caput, CF) e se referem à dimensão positiva do princípio da igualdade. Já o último mandamento deflui da previsão "sem distinção de qualquer natureza" (art. $5^{\circ}$, caput, e art. $3^{\circ}, \mathrm{IV}$; CF) e se refere à dimensão negativa do princípio da igualdade (2004, p. 235).

Por questão de método, invertendo a ordem exposta, a dimensão negativa do princípio da igualdade refere-se à determinação de proibição de qualquer tratamento discriminatório. Ou, em outros termos, a igualdade é norma de direito fundamental que propicia um direito subjetivo a todos os cidadãos a não sofrerem uma diferenciação injusta - contrária à dignidade humana - decorrente de algum preconceito acerca de determinadas características pessoais ou de grupos de pessoas. 
O princípio da igualdade, em sua dimensão negativa - ou como norma de proibição de discriminação -, opera de forma imediata (direta) nas relações entre particulares. Em decorrência disso, é vedada aos particulares a prática de quaisquer atos discriminatórios entre si, tendo por base cor, idade, religião, raça, origem, sexo ou outros atentatórios à dignidade das pessoas, notadamente pelo contido no inciso $\mathrm{XLI}$, do art. $5^{\circ}$ da Constituição: "a lei punirá qualquer discriminação atentatória dos direitos e liberdades fundamentais". Assim, mesmo não havendo cominação penal para determinado tipo de discriminação, no âmbito do direito privado há a possibilidade da indenização por danos extrapatrimoniais e/ou do restabelecimento do status quo anterior.

De seu turno, a dimensão positiva do princípio da igualdade, que engloba o mandamento de tratamento igual e o mandamento de tratamento desigual, é derivada do notório postulado aristotélico de justiça distributiva, tratando igualmente os iguais e desigualmente os desiguais.

Ora, esse postulado, por si só, é altamente indeterminado (corresponde àquilo que se convencionou chamar de conceito juridicamente indeterminado, ou, para alguns, noção indeterminada de conceito jurídico), provocando o que Bandeira de Mello chama de "intuitiva pergunta que aflora do espírito": "Quem são os iguais e quem são os desiguais?". Mais: “Qual o critério legitimamente manipulável - sem agravos a isonomia - que autoriza a distinguir pessoas e situações em grupos apartados para fins de tratamentos diversos?" (1984, p. 15).

Alexy, com base nos julgados do Tribunal Constitucional alemão, propõe dois mandamentos. Um, dispondo acerca do tratamento igual, qual seja: "Si no hay ninguna razón suficiente para lar permisión de un tratamiento desigual, entonces está ordenado un tratamiento igual" (1997, p. 395). E outro, acerca do tratamento desigual, a saber: "Si no hay ninguna razón suficiente para la permisión de un tratamiento igual, entonces está ordenado un tratamiento desigual"(1997, p. 396).

Eliseu Jusefovicz sustenta que "o legislador poderá levar a cabo certas discriminações sem violar o princípio da igualdade, desde que apresente 
justificadamente e sob a forma de normas universalistas" (2007, p. 416). E mais adiante, "entre os critérios para assegurar a isonomia constitucional na legislação, afirma-se que é necessário um 'vínculo lógico' entre a discriminação feita e o objeto a que se destina a lei, tendo em conta a situação fática" (2007, p. 417). Por sua vez, Carlos Alberto da Mota Pinto refere ser possível um tratamento desigual por parte da lei, desde que "fornecida uma justificação racional e objectiva, não arbitrária, da limitação do regime legal àquelas situações" (1999, p. 80).

Steinmetz diz que a justificação racional e objetiva da diferenciação ou tratamento desigual deverá ser obtida mediante um juízo de proporcionalidade, da seguinte forma:

\begin{abstract}
Antes de pôr em movimento o controle de proporcionalidade, identifica-se qual é, clara e precisamente, a relação meio-fim e examina-se a constitucionalidade do fim que se persegue ou se pretende promover com o tratamento desigual. Realizados esses exames prévios, examina-se, então, sucessivamente, ( $(\lambda)$ a adequação entre o meio (a própria diferenciação) e fim almejado (ii) a exigibilidade do meio e (iii) a proporcionalidade em sentido estrito entre os graus de afetação e de realização dos direitos e/ou bens constitucionais que estão em questão em virtude do tratamento diferenciado. Se a diferenciação ou tratamento desigual for reprovado no exame de proporcionalidade, então estará ordenado o tratamento igual. (STEINMETZ, 2004, p. 239-240).
\end{abstract}

Conseqüentemente, o princípio da isonomia, além de ser um mandamento passivo, passa a ser, também, um mandamento ativo. Ou seja, além da tradicional determinação de não discriminar, o princípio da igualdade, hoje, impõe ao Estado que adote medidas, através da legislação, em prol da redução das desigualdades materiais. "Passa-se a reconhecer que os homens não só têm direito a serem tratados igualmente, mas também o de se tornarem mais iguais" (ROSA, 2006, p. 459).

Vale dizer, a postura ativa do Estado não é mera conveniência; é, isto sim, um dever. Conforme alhures referido, é pressuposto do Estado Democrático de Direito, por erigir o fundamento à dignidade humana, atuar positivamente, promovendo a igualdade material mediante intervenções legislativas na órbita das relações privadas. 
Em suma, em se tratando da dimensão positiva, pode-se afirmar que são duas as análises a serem feitas: (a) se há ou não há razões suficientes para empregar um tratamento diferenciado; (b) havendo razões suficientes para regulamentar diferentemente, qual é o conteúdo normativo capaz de mitigar as desigualdades existentes. E justamente essa adequada avaliação propiciará a igualdade material entre as partes: "La igualdad material conduce, pues, necesariamente a la cuestión de la valoración correcta y, con ello, a la cuestión de qué es una legislación correcta, razonable o justa" (ALEXY, 1997, p. 388).

Nesse sentido, a igualdade material é princípio basilar e cogente, inclusive, nas relações contratuais, justificando uma tutela diferenciada do Estado à parte vulnerável (presumida ou comprovada), a fim de restabelecer o equilíbrio contratual, garantindo as justas expectativas das partes contratantes. Isso justifica a dinâmica e a mobilidade das posições subjetivas nos contratos, o que é alvitrado no próximo ponto deste trabalho.

2 Igualdade material em contratos tipicamente de consumo: nãonecessária incidência do Código de Defesa do Consumidor

Como premissa terminológica para compreensão do sentido pretendido, é necessário lembrar que, na prática, a tutela da parte vulnerável equivale à tutela do "hipossuficiente", daí por que os termos são tratados normalmente como sinônimos.

Há, claro, autores que diferem tais conceitos. Assim, para Tânia Lis Tizzoni Nogueira (2001, p. 97-8), bem como para José Reinaldo de Lima Lopes (1996, p. 77), a vulnerabilidade é uma condição de todos os consumidores imposta pela lei, ao passo que a hipossuficiência é plus à vulnerabilidade, ocorrendo em casos de agravamento da situação (relação envolvendo, por exemplo, crianças ou idosos). Já Cláudia Lima Marques limita o termo hipossuficiência a aspectos processuais, relacionando a vulnerabilidade a aspectos materiais (2002, p. 274). Em qualquer caso, a premissa deste trabalho trata a vulnerabilidade, por ser mais abrangente. 
Dito isso, é de sentir que a eficácia dos direitos fundamentais na visão hermenêutica integradora das formas privadas de trânsito jurídico implica redimensionar, em última análise, a dinâmica das posições subjetivas nos contratos (VALE, 2004, p. 122)

A liberdade contratual, que se consubstancia na máxima manifestação da autonomia privada, pode ser exercida em quatro níveis: (a) liberdade positiva e negativa de contratar, ou seja, liberdade de escolha se contrata ou não; (b) liberdade de escolha com quem contratar; (c) liberdade de escolha do tipo do contrato; e ainda (d) liberdade de escolha de conteúdo do contrato.

Com efeito, tais manifestações da liberdade contratual valem em sua integralidade exclusivamente para aqueles contratos ditos paritários, nos quais ambos os contratantes se encontram no mesmo nível negocial (igualdade material) e a sua gênese se dá através de longa e detalhada negociação. Obviamente essa não é, há tempos, a regra em nossa sociedade. As contratações em massa, decorrentes da produção e consumo em grande escala, implicaram o uso dos chamados contratos de adesão, nos quais um dos contratantes tão somente adere a um contrato previamente estabelecido pela outra parte, sem qualquer ingerência no seu conteúdo. Por outro lado, há fornecedores que detêm o monopólio de determinados produtos e serviços, ou seja, não há sequer a possibilidade de escolha.

Nesse panorama, nas relações de consumo (especialmente, mas não exclusivamente nelas), pode haver um evidente cerceamento à liberdade contratual da parte vulnerável; no caso, a liberdade é restrita a contratar ou não contratar e, por vezes, nem isso.

Buscando suprir esse anseio, como principal concretização legislativa do princípio da isonomia na esfera contratual, foi promulgado o Código de Defesa do Consumidor (Lei $n^{\circ}$ 8.078, de 11.09.1990). No caso, há uma tutela diferenciada do consumidor em face do fornecedor, buscando a adequação do contrato às justas expectativas das partes, ou, "reequilibrar a relação de consumo, seja reforçando, 
quando possível, a posição do consumidor, seja proibindo ou limitando certas práticas de mercado" (GRINOVER \& BENJAMIN, 1996, p. 7).

Essa diferenciação se dá pela presunção de que o consumidor, parte vulnerável nessa relação, ao contratar, teve a sua autonomia privada restringida em razão da superioridade do fornecedor. Pelo Código de Defesa do Consumidor, a tutela da parte presumidamente vulnerável trata-se de distinção legítima e constitucionalmente adequada, de vez que busca o restabelecimento da isonomia entre os contratantes, observando, por conseqüência, a dignidade humana.

Em suma, a ratio do Código de Defesa do Consumidor que regulamentou o intervencionismo do Estado na economia interna do contrato é tutelar especialmente o contratante débil, concretizando assim, os ditames da isonomia. "Trata-se [...] de uma necessária concretização do Princípio da Igualdade, de tratamento desigual aos desiguais, da procura de uma igualdade material e momentânea para um sujeito com direitos diferentes, sujeito vulnerável, mais fraco" (MARQUES, 2002, p. 218).

Nesse microssistema legislativo, na busca pelo equilíbrio das prestações, é nítida a redução da autonomia da vontade, já que os inúmeros dispositivos da Lei são, declaradamente, de ordem pública e, dessa forma, não podem ser alterados ou restringidos por convenção das partes. $\mathrm{Na}$ verdade, o Código Consumerista "celebra, antes de mais nada, o reconhecimento, pela legislação civil, da alteração do conceito de ordem pública, que assume um sentido emancipatório, pretendido pelo Texto Maior, voltado para a redução das desigualdades sociais e para a plena realização da pessoa humana" (TEPEDINO, 2006b, p. 351).

Nesse particular, ganha relevância a função do Poder Judiciário na dinâmica contratual, "pois, se as normas imperativas destas leis, aqui chamadas de intervencionistas, restringem o espaço da liberdade individual no contrato, também legitimarão ao Judiciário para que exerça o tão reclamado controle efetivo do conteúdo do contrato, controle da justiça contratual, em especial, o controle das cláusulas abusivas". (MARQUES, 2002. p. 308-309). Impõe-se, portanto, a 
intervenção estatal, no caso, pelo Poder Judiciário, a fim de proteger a vontade do sujeito mais fraco na relação e garantir o justo equilíbrio das prestações.

Questões que se colocam são: (a) como e (b) em que medida o Judiciário, quando acionado, poderá intervir na esfera interna do contrato, a fim de realizar a justiça contratual.

Quanto à primeira parte da indagação (o como), a resposta está calcada na nulidade das cláusulas abusivas, até porque é onde se evidencia a desigualdade na esfera contratual, no dizer de Cláudia Lima Marques: "a abusividade da cláusula contratual é o desequilíbrio ou descompasso de direitos e obrigações entre as partes, desequilíbrio de direitos e obrigações àquele contrato específico" (2002, p.148).

O Código de Defesa do Consumidor trata as cláusulas abusivas no seu artigo 51 , em rol que o caput se encarrega de qualificar como meramente exemplificativo (AGUIAR JUNIOR, 1994, p. 20), e cuja sanção é a nulidade de pleno direito.

Todavia, a exegese da amplitude dos poderes do Estado para tal controle tem sido vacilante na jurisprudência. De um lado, há manifestações autorizadoras da intervenção oficial, como acórdão do Superior Tribunal de Justiça assim ementado:

AGRAVO REGIMENTAL. CONTRATO DE FINANCIAMENTO. EXAME DE OFÍCIO. ART. 51, IV, CDC. COMISSÃO DE PERMANÊNCIA. LIMITAÇÃO AO PACTO. HONORÁRIOS ADVOCATÍCIOS. FIXAÇÃO DO VALOR EM FASE DE LIQUIDAÇÃO. REFORMATIO IN PEJUS. IMPOSSIBILIDADE. - A jurisprudência permite afastar, de ofício, as cláusulas abusivas com base no Art. 51, IV, do CDC, questão de ordem pública. [...] (STJ, Terceira Turma, AgRg no REsp 645902/RS, Data do julgamento: 28/09/2004, fonte/data da publicação: DJ 17.12.2004 p. 542 - REPDJ 01.02.2005 p. 556 Relator Ministro Humberto Gomes de Barros).

Logo, por se tratar de norma de ordem pública, é possível a decretação de ofício da nulidade mesmo em grau de recurso, afirmou o Tribunal de Justiça gaúcho: pleno direito daquelas cláusulas, torna-se obrigatório o reconhecimento de ofício do pactuado abusivamente, mesmo que não haja manifestação das 
partes, de acordo com o disposto no art.146, § único, do CCB (TJ/RS, Décima Quarta Câmara Cível, Apelação Cível n 70009188483, Relator Des. Rogério Gesta Leal, Data do Julgamento: 28.04.2005).

De outro lado, porém, no âmbito do próprio Superior Tribunal de Justiça, há acórdão da Segunda Seção a reduzir o poder do Estado, no exame das cláusulas abusivas, ao primeiro grau de jurisdição, inviabilizando seu exame de ofício em grau de recurso. Assim consta na ementa do provimento: "Exame de ofício de cláusulas contratuais pelo Tribunal de origem. Impossibilidade, por ofensa ao art. 515 do CPC. Princípio "tantum devolutum quantum appelattum" (STJ, Segunda Seção, Recurso Especial n. ${ }^{\circ} 541.153$ - RS, Relator Min. César Asfor Rocha, Data do Julgamento: 12.06.2005, Data da publicação / fonte: DJ 14.09.2005 p. 189).

Quanto à segunda parte da indagação (em que medida), a redefinição da igualdade na esfera das relações interprivadas depende da vulnerabilidade de um dos sujeitos da relação, a ser aferida pelo Estado no caso concreto. É dizer: circunstâncias especiais relacionadas à saúde, idade, conhecimento ou condição social devem ser levadas em conta na concreção do julgador, fazendo concreta a noção indeterminada do conceito de vulnerabilidade.

$E$ isso estende às pessoas jurídicas a noção de vulnerabilidade, vez que também essas podem sofrer abuso pela imposição de cláusulas e condições abusivas pela outra parte. Como decidiu o Superior Tribunal de Justiça:

Direito do Consumidor. Recurso especial. Conceito de consumidor. Critério subjetivo ou finalista. Mitigação. Pessoa Jurídica. Excepcionalidade. Vulnerabilidade. Constatação na hipótese dos autos. Prática abusiva. Oferta inadequada. Característica, quantidade e composição do produto. Equiparação (art. 29). Decadência. Inexistência. Relação jurídica sob a premissa de tratos sucessivos. Renovação do compromisso. Vício oculto.

- A relação jurídica qualificada por ser "de consumo" não se caracteriza pela presença de pessoa física ou jurídica em seus pólos, mas pela presença de uma parte vulnerável de um lado (consumidor), e de um fornecedor, de outro.

- Mesmo nas relações entre pessoas jurídicas, se da análise da hipótese concreta decorrer inegável vulnerabilidade entre a pessoa-jurídica consumidora e a fornecedora, deve-se aplicar o CDC na busca do equilíbrio entre as partes. Ao consagrar o critério finalista para interpretação do conceito de consumidor, a jurisprudência deste STJ também reconhece a necessidade de, em situações específicas, abrandar o rigor do critério subjetivo do conceito de consumidor, para admitir a aplicabilidade do CDC 
nas relações entre fornecedores e consumidores-empresários em que fique evidenciada a relação de consumo.

- São equiparáveis a consumidor todas as pessoas, determináveis ou não, expostas às práticas comerciais abusivas.

- Não se conhece de matéria levantada em sede de embargos de declaração, fora dos limites da lide (inovação recursal). Recurso especial não conhecido (STJ, Terceira Turma, REsp 476428/SC, Data do julgamento: 19/04/2005, fonte/data da publicação: DJ 09.05.2005 p. 390 Relatora Ministra Nancy Andrighi).

Nesse contexto, como premissa à concretização da igualdade material, devese observar a lição de Gustavo Tepedino: "O Código de Defesa do Consumidor fala em hipossuficiência econômica, conceito que deve ser entendido sempre de forma relativa, isto é, na concreta contraposição entre ambos os contratantes" (1999, p. 77).

Trata-se de arredar a concepção clássica que analisa abstratamente o sujeito, alocando-o dentro de determinadas categorias (consumidor/fornecedor, locador/locatário, arrendador/arrendatário, entre outros - o que não deixa de ser critério meramente formal de igualdade). Passa-se agora para a análise concreta do sujeito, entendendo-o como tal e levando em conta as suas particularidades.

Acerca da concepção que concebe o sujeito de forma abstrata e atomizada, diz Tereza de Negreiros: "tais normas são apenas aparentemente baseadas em circunstâncias pessoais, já que, numa relação jurídica entre, por exemplo, consumidor e fornecedor, pode acontecer que o consumidor seja a parte efetivamente forte" (NEGREIROS, 2006, p. 322). Assim, "mesmo o caso do direito de proteção ao consumidor é uma derrogação apenas parcial dos esquemas clássicos, já que, ao fim e ao cabo, também o conceito de consumidor resta abstrato" (NEGREIROS, 2006, p. 327).

Conseqüência disso é que, mesmo nas relações tipicamente de consumo, se o julgador, ao analisar o caso concreto, não verificar a vulnerabilidade do consumidor (por ser ele hipersuficiente), não poderá tutelá-lo de forma diferenciada. Afinal, é certo que a proteção especial ao consumidor é direito fundamental, elencado na carta constitucional em seu art. $5^{\circ}, \mathrm{XXXII}$, não sendo possível, de regra, abdicar do tratamento protetivo estabelecido no $\mathrm{CDC}$. Ocorre que a proteção especial ao 
consumidor pressupõe, a partir de uma análise minimamente sistemática do ordenamento constitucional, a condição de vulnerabilidade. Não se verificando essa condição, não há que se falar em tratamento diferenciado.

Em outros termos, pode-se entender, em dado caso concreto, que não persiste a razão constitucionalmente adequada que levou o legislador a proteger a classe dos consumidores, tutelando-os diferentemente em prol da igualdade material: a opção legislativa é afastada, então, porque a parte, mesmo sendo destinatário final da relação de consumo, não se mostra vulnerável.

E para a não aplicação das regras constantes no Código de Defesa do Consumidor na circunstância referida, impõe-se entender que as regras, assim como os princípios, possuem uma dimensão de peso e, conseqüentemente, podem ser afastadas sem que isso implique a sua completa retirada do sistema. Ou seja, as regras da legislação consumerista podem continuar válidas abstratamente, porém concretamente não serão aplicadas, pois, no caso, não estarão atendendo a sua função precípua (fundamentos originários) de dirimir as desigualdades. Ao invés disso, estarão a gerá-las em favor de quem não necessita delas (o consumidor hipersuficiente).

Faz-se empréstimo da teoria propugnada por Humberto Ávila (2006, 114-120): identificando as razões que impõem a observância da regra protetiva, "ligadas à segurança jurídica e à previsibilidade do Direito, e as razões que justificam o seu abandono em favor da investigação dos fundamentos mais ou menos distantes da própria regra" (ÁVILA, 2006, p. 58), escolhe-se o segundo caminho.

A orientação do Superior Tribunal de Justiça tem feito eco a tal tese, como se vê pelos acórdãos ementados a seguir:

COMPETÊNCIA. Cláusula de eleição de foro. Equipamentos médicohospitalares. Empresa de porte. A clínica médica que adquire equipamento de valor acima de um milhão de dólares tem, presumidamente, condições de exercer a sua defesa no foro de São Paulo, previsto no contrato. Precedente. Recurso conhecido e provido. (REsp 457398/SC, Rel. Ministro Ruy Rosado de Aguiar, Quarta Turma, julgado em 12.11.2002, DJ 
09.12.2002 p. 357) Processual civil. Competência. Foro de eleição. Contrato para aquisição de modernos equipamentos médico-hospitalares. Hipossuficiência não configurada. Precedente da $2^{\mathrm{a}}$ Seção. Decisão agravada confirmada. Agravo regimental desprovido. (AgRg nos EDcl no REsp 561853/MG, Rel. Ministro Antônio de Pádua Ribeiro, Terceira Turma, julgado em 27.04.2004, DJ 24.05.2004 p. 270)

Isso, longe de afetar a justiça geral, corolário da dignidade humana (do que a igualdade material é vetor), mais a reafirma, harmonizando as tensões do sistema, visto que, se a aplicação da regra protetiva pressupõe a vulnerabilidade do consumidor, não existindo esta, não deverá ser aplicada aquela, sob pena do risco inverso (violar-se a dignidade do fornecedor). A aplicação pura e simples do diploma protetivo seria grave arbitrariedade, aprofundando a desigualdade entre os contratantes, não pela sua condição, como no Estado liberal, mas sim (de forma mais ultrajante ao Direito), pela força da lei.

\section{Igualdade material em outros contratos: a possibilidade de incidência do Código de Defesa do Consumidor}

$\mathrm{Na}$ esteira da concretização da isonomia substancial nas relações contratuais, impõe-se indagar ainda: (a) como pode (ou deve) ocorrer essa concretização nas relações notadamente desiguais e que não se enquadram na tipificação tradicional de relação de consumo? e (b) no caso de ausência de intermediação legislativa própria, poderá o princípio da igualdade, em sua dimensão positiva, incidir diretamente nas relações privadas que evidenciem disparidades?

Diferentemente da dimensão negativa da isonomia (cuja eficácia direta ou imediata nas relações entre particulares é ponto pacífico na doutrina), põe-se em dúvida a possibilidade de atuação judicial em prol da concretização imediata da dimensão positiva da isonomia. Nas relações interprivadas, a regra é a prevalência da liberdade contratual, decorrente da autonomia privada. Assim, distintamente das relações entre o Estado e o particular, no âmbito privado não carece ao particular dever, sempre, justificar racional e objetivamente um tratamento igual ou desigual.

Juan María Bilbao Ubillos tem a mesma preocupação: 
Porque existe una esfera de actuación puramente privada, un reducto de vida auténticamente privada, que queda fuera del alcance de las normas constitucionales, en el que los individuos son libres de discriminar a la hora de seleccionar las personas con las que van a relacionarse (pueden invitar a su casa o a una fiesta a quien crean conveniente, asociarse con quienes deseen y negarse a entrar en un determinado establecimiento, por los motivos que sean), de regular esas relaciones (determinando el contenido de los contratos, de los estatutos sociales o de las disposiciones testamentarias) y de comportarse, en general, de una manera que le está vedada al Estado. (2005, p. 362).

Mais adiante, adverte o jurista espanhol: "extender al ámbito de las relaciones jurídico-privadas el principio constitucional de igualdad, una regla ajena a este mundo, pude acarrear consecuencias absurdas e insoportables" (2005, p. 362). Até porque, mesmo para os partidários da eficácia imediata dos direitos fundamentais nas relações privadas, como o próprio Ubillos, o princípio da igualdade, como norma de direito fundamental, não é absoluto:

La existencia de determinados límites no tiene nada de extraordinario. Los derechos fundamentales tampoco son ilimitados cuando se esgrimen frente al poder público. En esta dimensión, ningún derecho se impone de forma absoluta e inapelable, automáticamente, en cualquier circunstancia. (UBILLOS, 2005, p. 363).

E é justamente por isso que, quase sempre (e recomendável que seja), a limitação da autonomia privada decorrente do princípio da igualdade é feita mediante legislação infraconstitucional, como, por exemplo, na situação antes referida (do Código de Defesa do Consumidor). Relembrando, trata-se de um sopesamento prévio do legislativo, (a) elegendo quais os casos que merecem distinção e (b) indicando como será feita essa distinção de forma a mitigar as desigualdades existentes.

Não obstante, há situações que, desprovidas de mediação legislativa, exigem tratamento diferenciado aos desiguais, em virtude das peculiaridades da relação. Aqui, a razão constitucionalmente adequada é a disparidade entre os contratantes, levando-se em conta, não a simples condição de consumidor, empregado, arrendatário ou locatário, mas sim, a situação concreta de vulnerabilidade. Sendo assim, quanto maior for a assimetria na relação, menor terá sido a real manifestação 
da vontade do contratante débil e, conseqüentemente, maior deverá ser a necessidade de sua proteção, restringindo, dessa forma, a autonomia privada.

Para Steinmetz, excepcionalmente, em alguns casos, os particulares estão vinculados à dimensão positiva do princípio da igualdade, independentemente de legislação infraconstitucional. Segundo ele, casos tais carecem de justificação racional e objetiva, mensurável pelo princípio da proporcionalidade. (2004, p. 263).

Assim resolvido o primeiro problema - vulnerabilidade fática como razão suficiente para um tratamento desigual -, impõe-se agora passar à análise da segunda questão proposta, qual seja, como concretamente deverá incidir o princípio da igualdade em sua dimensão positiva. Como visto alhures, na esteira de Steinmetz, inexistindo legislação infraconstitucional que concretize o direito fundamental, ou sendo o caso de inobservância dessa legislação, a incidência do direito à igualdade é imediata, sendo, entretanto, "matizada" ou "modulada" pela ponderação de bens, aferível pelo princípio da proporcionalidade.

$\mathrm{Na}$ situação posta, a constatação óbvia, em primeiro plano, é transpor a primeira fase e mensurar como se dará a aplicação da igualdade, com a conseqüente restrição à autonomia privada, mediante $\circ$ princípio da proporcionalidade. Observa-se que "nesses tipos de situação há uma precedência prima facie do princípio da igualdade e um ônus de argumentação para o princípio da autonomia privada" (STEINMETZ, 2004, p. 263).

Parece, entretanto, desnecessário recorrer a tanto; tratando especificamente o princípio da isonomia nas relações contratuais, pode-se dizer que o legislador já fez essa ponderação quando da gênese do Código de Defesa do Consumidor. Conforme se pôde observar até aqui, a razão constitucionalmente adequada para tratamento distinto entre partes contratantes, relação de consumo ou não, é a mesma, ou seja, primar pelo restabelecimento da isonomia material entre as partes, preservando, por conseguinte, o valor fundamental da dignidade da pessoa humana (artigo $1^{\circ}, \mathrm{III}$, da CF). Por conseguinte, é aplicável o Código de Defesa do 
Consumidor às relações em que uma das partes se mostra concretamente vulnerável, independentemente da abstrata condição de consumidor.

Calha dizer que a opção pela legislação consumerista nestes casos de vulnerabilidade fática mostra-se mais adequada do que a opção pela ponderação do intérprete, e isso por três razões: (a) a segurança jurídica, (b) o comprovado alcance do fim almejado e (c) o mandamento de tratamento igual aos iguais.

Considerando a maior determinação das regras, é inegável que um sistema constituído majoritariamente por essas normas propicia maior segurança jurídica aos seus destinatários do que um sistema constituído predominantemente por princípios, estes caracterizados pela indeterminação. Quanto mais o conteúdo da norma for difuso e, conseqüentemente, essa mensuração ficar a cargo do julgador, menor será a previsibilidade da decisão. (ALEXY, 1997, p. 115-135).

Todavia, de nada valerá tal segurança se as regras não responderem aos anseios da justiça no caso concreto. Anseios propiciados pela adequada aplicação das normas princípios.

Na situação em comento, não há de se olvidar que o Código de Defesa do Consumidor está entranhado de cláusulas gerais que, de certa forma, oxigenam o sistema. Ademais, esse microssistema veio justamente densificar normativamente o princípio da isonomia material, dessa forma, prima facie, ele estará atendendo aos anseios da justiça. Por outro lado, caso não atenda, conforme foi anteriormente sustentado, também as regras, excepcionalmente, podem ser ponderadas.

E este último argumento se relaciona com a segunda razão para preferência aplicativa do Código em face do princípio de forma imediata, ou seja, a inegável constatação de que a legislação consumerista está cumprindo com o seu intento. Com ela, "Sonhava-se com um mundo mais isonômico no mercado de consumo e se procurava exorcizar, a todo o custo, a lógica individualista (que se supunha perene) do direito privado" (TEPEDINO, 2006a, p. 406). Em sua vigência, “desempenhou, então, o CDC o papel deflagrador de um repensar crítico do direito privado, criando 
nos anos 90 um movimento conhecido como consumerismo, que procura se afastar ao máximo da dogmática liberal e patrimonialista do direito civil tradicional” (TEPEDINO, 2006a, p. 405).

Por fim, como última razão à preferente aplicação do Código de Defesa do Consumidor, está o mandamento de tratamento igual aos iguais, ou, como refere Alexy: "si no hay ninguna razón suficiente para lar permisión de un tratamiento desigual, entonces está ordenado un tratamiento igual" (1997, p. 395). Ora, se concretamente o consumidor e o contratante débil, mesmo não consumidor, são iguais, ou seja, ambos possuem a mesma "'identidade', no aspecto decisivo para valoração jurídica" (situação concreta de vulnerabilidade) (JUSEFOVICZ, 2007, p. 430), impõe-se o mesmo tratamento da lei.

Feita essa abordagem, calha dizer, neste passo, que a doutrina consumerista já trava essa discussão, porém sob outra ótica; a do conceito de consumidor. $\mathrm{O}$ artigo $2^{\circ}$ da Lei $n^{\circ} 8.078$, de 11.09.1990, estabelece o conceito legal de consumidor: "Consumidor é toda pessoa física ou jurídica que adquire ou utiliza produto ou serviço como destinatário final [...]". A partir de uma leitura isolada e exegeta do referido dispositivo de lei, poder-se-ia concluir que todos aqueles contratantes que não adquirem o produto para uso pessoal e de sua família não estão protegidos pelas normas da legislação protetiva. No entanto, a doutrina se divide em duas vertentes. A primeira, chamada de finalista (ou minimalista), sustenta justamente essa conclusão.

Em jurisprudência, a $2^{\mathrm{a}}$ Seção do Superior Tribunal de Justiça firmou entendimento que restringe a figura de consumidor àquele que adquire um produto para uso próprio (destinatário final):

COMPETÊNCIA. RELAÇÃO DE CONSUMO. UTILIZAÇÃO DE EQUIPAMENTO E DE SERVIÇOS DE CRÉDITO PRESTADO POR EMPRESA ADMINISTRADORA DE CARTÃO DE CRÉDITO. DESTINAÇÃO FINAL INEXISTENTE.

- A aquisição de bens ou a utilização de serviços, por pessoa natural ou jurídica, com o escopo de implementar ou incrementar a sua atividade negocial, não se reputa como relação de consumo e, sim, como uma atividade de consumo intermediária. Recurso especial conhecido e provido 
para reconhecer a incompetência absoluta da Vara Especializada de Defesa do Consumidor, para decretar a nulidade dos atos praticados e, por conseguinte, para determinar a remessa do feito a uma das Varas Cíveis da Comarca. (STJ, Segunda Seção, REsp 541867/BA, Data do julgamento: 10/11/2004, fonte/data da publicação: DJ 16.05.2005 p. 227, Relator Ministro Antônio de Pádua Ribeiro, Relator p/ Acórdão Ministro Barros Monteiro)

Porém, a teoria finalista foi mitigada pelo próprio Superior Tribunal de Justiça, ao estender a proteção da Lei $n^{\circ} 8.078$ a empresa comprovadamente vulnerável e destinatária final da relação:

Direito do Consumidor. Recurso especial. Conceito de consumidor. Critério subjetivo ou finalista. Mitigação. Pessoa Jurídica. Excepcionalidade. Vulnerabilidade. Constatação na hipótese dos autos. Prática abusiva. Oferta inadequada. Característica, quantidade e composição do produto. Equiparação (art. 29). Decadência. Inexistência. Relação jurídica sob a premissa de tratos sucessivos. Renovação do compromisso. Vício oculto.

- A relação jurídica qualificada por ser "de consumo" não se caracteriza pela presença de pessoa física ou jurídica em seus pólos, mas pela presença de uma parte vulnerável de um lado (consumidor), e de um fornecedor, de outro.

- Mesmo nas relações entre pessoas jurídicas, se da análise da hipótese concreta decorrer inegável vulnerabilidade entre a pessoa-jurídica consumidora e a fornecedora, deve-se aplicar o CDC na busca do equilíbrio entre as partes. Ao consagrar o critério finalista para interpretação do conceito de consumidor, a jurisprudência deste STJ também reconhece a necessidade de, em situações específicas, abrandar o rigor do critério subjetivo do conceito de consumidor, para admitir a aplicabilidade do CDC nas relações entre fornecedores e consumidores-empresários em que fique evidenciada a relação de consumo.

- São equiparáveis a consumidor todas as pessoas, determináveis ou não, expostas às práticas comerciais abusivas.

- Não se conhece de matéria levantada em sede de embargos de declaração, fora dos limites da lide (inovação recursal). Recurso especial não conhecido (STJ, Terceira Turma, REsp 476428/SC, Data do julgamento: 19/04/2005, fonte/data da publicação: DJ 09.05.2005 p. 390 Relatora Ministra Nancy Andrighi).

Aproxima-se, aqui, da segunda vertente doutrinária, dita maximalista, em que o conceito de consumidor deve ser amplo. Os seguidores da referida doutrina, os denominados maximalistas, vêem nas normas do CDC o novo regulamento do mercado de consumo brasileiro, e não normas orientadas para proteger somente o consumidor não profissional. Nesse caso o CDC seria um Código geral sobre o consumo, seria, na verdade, um Código para a sociedade de consumo, que institui normas e princípios para todos os agentes do mercado, os quais podem assumir os papeis ora de fornecedores ora de consumidores. "Segundo esta corrente, a 
definição do art. $2^{\circ}$ é puramente objetiva, não importando se é pessoa física ou jurídica tem ou não tem fim de lucro quando adquire um produto ou utiliza um serviço. Destinatário final seria o 'destinatário fático' do produto, aquele que retira do mercado e o utiliza, o consome". (EFING, 2000, p. 46).

A tese não parece ter correspondência, no entanto, com o artigo $2^{\circ}$ do Código de Defesa do Consumidor, vez que, ali, claramente, há opção pelo destino "final" do produto ou serviço adquirido ou contratado. Aliás, essa confissão é feita por Alinne Arquette Leite Novais, em dissertação de mestrado orientada pelo Professor Gustavo Tepedino, na qual propõe a incidência das regras protetivas consumeristas para todo e qualquer contrato de adesão, independentemente de o aderente ser, ou não, destinatário final da relação, em virtude, não do artigo $2^{\circ}$, mas do artigo 29 daquele Código, cuja redação é esta: "Para os fins deste Capítulo e do seguinte, equiparam-se aos consumidores todas as pessoas determináveis ou não, expostas às práticas nele previstas". Isto é: a autora parte do pressuposto de que o aderente de um contrato elaborado prévia e unilateralmente é presumivelmente vulnerável (2001, p. 152-160).

Discordando da posição acima, Cláudia Lima Marques, eminente defensora da corrente finalista, ao prefaciar a obra da citada autora, sustenta que o método de contratação por adesão per se levaria o julgador a considerar (de consumo) a relação mesmo que interempresarial, uma vez que foi a superioridade econômica e fática de um que permitiu a utilização desse método e a elaboração unilateral do contrato por aquele na posição mais forte (Machtposition), a caracterizar suficientemente a vulnerabilidade do outro, como exige o art. $4^{\circ}$, I, do CDC. Cláudia Lima Marques, defende a interpretação finalista com base na vulnerabilidade, seja ela presumida ou comprovada. (NOVAIS, 2001, p. 19-20).

Cotejando os sólidos argumentos trazidos pelas autoras, discorda-se da afirmação de Aline Novais de que a simples adesão a um contrato com cláusulas pré-estabelecidas é suficiente para presumir a vulnerabilidade da parte e, conseqüentemente, tutelar diferentemente este contratante. 
De outro lado, em consonância com o que foi sustentado até aqui, conclui-se assistir razão a Alinne Novais no que tange à ampliação da incidência do Código de Defesa do Consumidor, "em virtude da unidade do ordenamento jurídico, assegurado pela própria Constituição Federal” (NOVAIS, 2001, p. 30). Trata-se de realizar a hermenêutica integradora, partindo do princípio de que o sistema jurídico é um conjunto único de normas que tem a Constituição como norma fundamental. Logo, é possível sustentar a ampliação da incidência das regras protetivasconsumeristas a partir de uma interpretação maximalista do artigo 29 do CDC, não na condição de aderente contratual, mas na condição de parte vulnerável, segundo as circunstâncias do caso concreto. As teses, assim, são complementares e não excludentes entre si.

As teses avultam de importância mesmo após a promulgação do Código Civil de 2002, cujo escopo, na concepção do Professor Miguel Reale, são os valores ético-solidaristas (MARTINS-COSTA \& BRANCO, 2002. p. 130-160). Com efeito, são inegáveis os dispositivos trazidos pela nova legislação civil buscando dirimir um pouco a disparidade entre os contratantes, merecendo destaque os artigos 421 que trata da função social do contrato, 422 que trata da boa-fé objetiva, 423 que trata da forma de interpretação de cláusulas ambíguas ou contraditórias dos contratos de adesão e 424 que, também se referido aos contratos de adesão, dispõe serem nulas as cláusulas que estipulem a renúncia antecipada do aderente a direito resultante da natureza do negócio.

Todavia, em relação ao controle de cláusulas abusivas, o legislador civil foi tímido. Limitou-se ao referido artigo 424, cuja incidência está restrita aos contratos de adesão. Por evidente, existe enorme lacuna em relação às demais relações, nas quais o contrato não se configure tipicamente como de adesão, e nas quais poderá ocorrer, entretanto, a vulnerabilidade de um dos contratantes.

Pelo que ficou registrado, fica claro que a falta de previsão expressa no Código Civil não significa deixar ao desamparo a parte vulnerável. Além da incidência do princípio da isonomia substancial, Código Civil e Código de Defesa do Consumidor não se excluem. Ao invés, complementam-se pelo chamado "diálogo das fontes", conforme dispõe Gustavo Tepedino: "O Código Civil e o Código de Defesa do 
Consumidor não podem ser considerados diplomas contrastantes senão complementares, no âmbito da complexidade do ordenamento, instrumentos para a promoção da solidariedade e do personalismo constitucionais". (2006, p. 406).

Diante dessas circunstâncias, afirma Tepedino "que o novo diploma civil destina-se a regular relações estabelecidas entre contratantes paritários, voltando-se as normas do Código de Defesa do Consumidor para a disciplina dos contratos de consumo e das práticas comerciais entre partes desigualmente situadas". (TEPEDINO, 2006, p. 408).

A nova racionalidade, que tem como vértice a Constituição, constrói, assim, um sistema aberto e móvel, no qual a proteção da parte mais vulnerável é adequada à realidade do caso concreto. Isso implica aumento do poder do magistrado, buscando a eqüidade pelo controle das cláusulas abusivas no direito contratual como um todo, intervindo na esfera interna do contrato a fim de primar pelas justas expectativas dos contratantes.

É necessário, pois, mudança na compreensão do papel do Estado/Juiz no controle da igualdade, e é necessário, também, mudança no próprio conceito de igualdade, tornado dinâmico. Só pode ser aferido diante das peculiaridades dos sujeitos envolvidos na relação contratual, preservando, com isso, a dignidade das pessoas envolvidas em tais formas privadas de trânsito jurídico, valor maior do qual decorrem todos os outros elementos axiológicos e principiológicos do sistema jurídico.

\section{CONCLUSÃO}

A racionalidade contratual liberal, na qual se presumia a igualdade formal dos contratantes, é um modelo ultrapassado, posto que falacioso diante dos fatos sociais. O respeito irrestrito ao contrato, decorrente da livre manifestação da vontade, não é - nem pode ser - visto como dogma inabalável. A exteriorização da vontade na sociedade cada vez mais desigual e injusta nem sempre é tão livre 
quanto propugnado pelos liberais, e conseqüentemente não corresponde necessariamente à vontade real da parte.

As intervenções pontuais na legislação contratual efetivadas pelo Estado dito "Social" mostraram-se insuficientes, especialmente no Brasil, por manterem o valor da pessoa pelo ter e não pelo ser, e por preservarem os interesses da sociedade capitalista, ao invés de diminuírem as desigualdades sociais.

Com isso, entra em crise também a própria fonte do Direito por excelência, a lei, entendida aqui como código. Idealizado sob os auspícios de um racionalismo intransigente, que tornava o legislador o único intérprete autorizado a exprimir a vontade do Estado, é colocado em xeque pelas novas condições humanas e sociais, não contidas em incunábulos. Constata-se então a distinção entre texto e norma, já que a interpretação é algo mais que mera subsunção, ou operação lógico-formal de caráter dedutivo.

Neste passo, a participação do intérprete, com sua pré-compreensão, é essencial à obtenção do sentido do texto para o caso concreto. $E$ a referência maior para a interpretação está na Constituição Federal, elemento fundante e vértice do sistema jurídico. Fala-se, pois, em Estado Constitucional, numa revolução copernicana, visto que é justamente a Constituição Federal de 1988 que assume uma postura de transformação da realidade social, irradiando sobre toda a ordem jurídica os seus valores democráticos.

Passam a importar os direitos fundamentais como núcleos da Constituição, com estrutura normativa de princípios, aí assumindo lugar imprescindível a dignidade humana, de que é consectário a igualdade (material e não meramente formal). Todavia, a validade e a eficácia das declarações contidas no texto constitucional dependem da forma de sua aplicação às diversas situações interprivadas, notadamente aqui às relações contratuais.

Crê-se que a aplicação das normas jusfundamentais às relações entre particulares deva ocorrer de forma diversa, conforme exista ou não exista legislação 
infraconstitucional. Assim é que, havendo mediação legislativa (ou regulamentação específica concretizadora do direito fundamental), deverá aquela, em princípio, ser aplicada, respeitando a separação dos Poderes e o princípio democrático.

Se, no entanto, a regulamentação específica for inconstitucional ou insuscetível de interpretação conforme à Constituição (Verfäßungskonforme Äuslegung), deverá ser aplicado diretamente o direito fundamental, mediante recurso à ponderação de interesses (aferível por proporcionalidade e seus desdobramentos: adequação, necessidade e proporcionalidade em sentido estrito).

O mesmo pode ser dito, de maneira abrangente, se restar demonstrada a dissociação entre a regulamentação específica e a finalidade para a qual foi projetada, isto é, se não existir correspondência entre o caso concreto e a hipótese (fundamento originário levado em conta pelo legislador) de incidência da regra. Neste caso, a ressalva diz respeito apenas à questão da segurança jurídica, visto que de exceção não se pode transformar em corriqueira. E aqui também se faz uso da ponderação, assim, não permanecendo exclusiva para os princípios, mas restando ampliada - em casos excepcionais - para as regras. Na colisão, a regra, em si, continua válida; no caso concreto, porém, sua incidência será afastada, de acordo com determinadas condições materiais e procedimentais (em especial, justificativa e comprovação condizentes).

Nessa perspectiva, importantes influxos sofre o contrato, abeberado agora em onda na qual the cumpre ser elemento de dinâmica e não de estática social. $A$ hermenêutica crítica e socialmente justificada e justificável deixa ao intérprete a possibilidade de, concretamente, dirimir desigualdades materiais entre os contratantes.

A abertura hermenêutica para redimensionar as relações contratuais é dada, mais uma vez, pela ponderação entre o direito fundamental afetado e a autonomia privada, esta última também constitucionalmente tutelada. Aqui, a colisão remete às precedências prima facie, as quais, ao levarem em conta três planos (normativo, analítico e empírico), permitem estabelecer que, em caso de relação contratual de 
particulares em situação, quer de igualdade, quer de desigualdade fática, haverá precedência prima facie do direito fundamental individual de conteúdo pessoal ante o princípio da autonomia privada. Da mesma forma, estando-se diante de relação contratual de particulares em situação de desigualdade fática, o direito fundamental individual de conteúdo patrimonial terá precedência prima facie diante do princípio da autonomia privada.

Apenas no caso de a relação contratual dar-se entre particulares em situação de igualdade fática, e tendo conteúdo patrimonial o direito fundamental, é que se poderá falar em precedência prima facie do princípio da autonomia privada em relação àquele direito fundamental considerado.

Já no caso específico da igualdade material, há que se considerar que, para além da dimensão fundamental negativa (proibição de discriminação), revela-se hoje conteúdo eminentemente positivo, com a necessidade de tratamento igual aos iguais e desigual aos desiguais. E, passo essencial, tem-se o Código de Defesa do Consumidor, que, ao tutelar diferentemente a parte vulnerável (aqui protegida de forma explícita), pondera previamente a colisão em matéria contratual.

A mediação legislativa exercida pelo Código Consumerista controla cláusulas abusivas e intervém na dinâmica contratual para garantir as justas expectativas das partes contratantes. Quanto menor for a autonomia, maior será a necessidade de proteção pelo Estado, o que remete à aferição da vulnerabilidade de acordo com o caso concreto.

Assim, quando não houver vulnerabilidade do contratante (ainda que, teoricamente, pudesse ser enquadrado em categoria protegida de forma expressa, como consumidor, empregado, etc.), tem-se aí razão suficiente para o afastamento da norma protetiva. Afinal, não só os princípios, mas também as regras possuem uma dimensão de peso e, conseqüentemente, podem ser afastadas sem que isso implique a sua completa exclusão do sistema.

Ao invés, mesmo nas relações em que não há típica relação de consumo, é possível incluir, sob o manto da proteção consumerista, toda parte que, ainda que 
não autêntica "consumidora" (por não estar subsumida no artigo $2^{\circ}$ do CDC), esteja em situação de vulnerabilidade frente à outra. Como razões suficientes a tanto, entram em voga, de um lado, a segurança jurídica (pela maior determinação das regras, com reflexos na previsibilidade das decisões judiciais), o comprovado alcance do fim protetivo almejado e o mandamento de tratamento igual aos iguais, e, de outro lado, a interpretação maximalista do conceito de consumidor (decorrente do artigo 29 do CDC).

Assim, a aplicação ampliada e protetiva do CDC, porém matizada de acordo com o caso concreto, é um importante vetor de concretização da hermenêutica principiológica constitucional, tornando dinâmicas as posições subjetivas contratuais. Através de tal aplicação, consubstancia-se a busca da igualdade material, por tanto tempo restrita ao âmbito de mero regramento formal.

\title{
EQUALITY CONTRACT IN BRAZILIAN LAW: NEW RACIONALITY And HERMENEUTICS THE CONSTITUTIONAL PRISM
}

\begin{abstract}
The study deals with the reinterpretation of the material equality contracts, based on the historical verification of equality, linked to rationalism, stresses the need to overcome liberal ideas and therefore uncompromises with reality, because its maintain the status quo. The concept of equality in this aspect (material) depends on the actual vulnerability of the contractor, to be verified in this case, without falling, however, a decisionism or a relativism (away by the last condition for legitimacy of the state act: the judgement motivation).
\end{abstract}

Keywords: Constitutionalisation of Private Law. Contract. Equality. 
1 Advogado, Pós-Doutor em Direito pela Universidade de Salerno-Itália, Professor do Programa de Pós-Graduação em Direito - Mestrado da UNISC, Coordenador do Grupo de Estudos e Pesquisas "A Constitucionalização do Direito Privado" .

2 Advogado, Mestre em Direito, Professor da Graduação em Direito da Fadisma, Pesquisador do Grupo de Estudos e Pesquisas "A Constitucionalização do Direito Privado".

\section{REFERÊNCIAS}

AGUIAR JÚNIOR, Ruy Rosado de. Cláusulas abusivas no Código de Defesa do Consumidor. In: MARQUES, Cláudia Lima (Org.). Estudos sobre a proteção do consumidor no Brasil e no Mercosul, Porto Alegre: Livraria do Advogado, 1994.

ALEXY, Robert. Teoría de los derechos fundamentales. Traduzido por Ernesto Garzón Valdés, Madrid: Centro de Estudios Constitucionales, 1993.

. Teoría de los derechos fundamentales. Traduzido por Ernesto Garzón Valdés, Madrid: Centro de Estudios Constitucionales, 1997.

ÁVILA, Humberto Bergmann. Teoria dos princípios: da definição à aplicação dos princípios jurídicos. 2. ed. São Paulo: Malheiros, 2003.

- Teoria dos princípios: da definição à aplicação dos princípios jurídicos. 3. ed.

São Paulo: Malheiros, 2004.

. Teoria dos princípios: da definição à aplicação dos princípios jurídicos. 6. ed.

São Paulo: Malheiros, 2006.

BANDEIRA DE MELLO, Celso Antônio. O conteúdo jurídico do princípio da igualdade. 2. ed. São Paulo: Revista dos Tribunais, 1984.

EFING, Antônio Carlos. Contratos e procedimentos bancários à luz do Código de Defesa do Consumidor. São Paulo: Revista dos Tribunais, 2000.

GRINOVER, Ada Pellegrini; BENJAMIN, Antônio Herman de Vasconcellos e. Visão geral do código. In: GRINOVER, Ada Pellegrini, et al. Código de Defesa do Consumidor comentado pelos autores do anteprojeto. 4. ed. Rio de Janeiro: Forense Universitária, 1996.

JUSEFOVICZ, Elizeu. Contratos - proteção contra cláusulas abusivas. Curitiba: Juruá, 2007.

LOPES, José Reinaldo de Lima. Responsabilidade do Estado por empresas fiscalizadas. Revista de direito do consumidor, São Paulo, v. 18, p. 77-93, abr./jun. 1996.

. O Direito na História: lições introdutórias. 2. ed. São Paulo: Max Limonad, 2002. 
MARQUES, Cláudia Lima. Contratos no Código de Defesa do Consumidor. 4. ed. São Paulo: Revista dos Tribunais, 2002.

Contratos no Código de Defesa do Consumidor. São Paulo: Revista dos Tribunais, 1999.

MARTINS-COSTA, Judith. A boa-fé no direito privado. São Paulo: Revista dos Tribunais, 1999. 2002.

(Org.). A reconstrução do direito privado, São Paulo: Revista dos Tribunais,

NEGREIROS, Teresa. Teoria do contrato - novos paradigmas. 2. ed. Rio de Janeiro: Renovar, 2006.

NOGUEIRA, Tania Lis Tizzoni. Contrato verbal de consumo. Curitiba: Juruá, 2001.

NOVAIS, Alinne Arquette Leite. A Teoria Contratual e o Código de Defesa do Consumidor. São Paulo: Revista dos Tribunais, 2001.

PINTO, Carlos Alberto Mota. Teoria geral do direito civil. 3. ed. Coimbra: Coimbra, 1999.

REIS, Jorge Renato dos. A concretização e a efetivação dos direitos fundamentais no direito privado. In: LEAL, Rogério Gesta \& REIS, Jorge Renato dos (Org.).

Direitos sociais e políticas públicas: desafios contemporâneos. Santa Cruz do Sul, RS: Edunisc, 2004. t. 4.

A vinculação dos particulares aos direitos fundamentais nas relações interprivadas: breves considerações. In: LEAL, Rogério Gesta \& REIS, Jorge Renato dos (Org.). Direitos sociais e políticas públicas: desafios contemporâneos. Santa Cruz do Sul, RS: Edunisc, 2005. t. 5.

ROSA; André Vicente Pires. Igualdade. In: BARRETTO, Vicente de Paulo (Coord.). Dicionário de filosofia do direito. São Leopoldo/Rio de Janeiro: Unisinos/Renovar, 2006.

SARLET, Ingo Wolfgang. A eficácia dos direitos fundamentais. Porto Alegre: Livraria do Advogado, 1998.

. Direitos Fundamentais e Direito Privado: algumas considerações em torno da vinculação dos particulares aos direitos fundamentais. In: SARLET, Ingo Wolfgang (Org.). A Constituição concretizada: construindo pontes com o público e o privado, Porto Alegre: Livraria do Advogado, 2000.

STEINMETZ, Wilson. $A$ vinculação dos particulares aos direitos fundamentais. São Paulo: Malheiros Editores, 2004. 
TEPEDINO, Gustavo. Crise das fontes normativas e técnica legislativa na parte geral do Código Civil de 2002. In: TEPEDINO, Gustavo (Coord.). A parte geral do novo Código Civil / Estudos na perspectiva civil-constitucional, Rio de Janeiro: Renovar, 2002.

. O Código Civil, os chamados micro sistemas e a Constituição: premissas para uma reforma legislativa. In: TEPEDINO, Gustavo (Org.). Problemas de Direito Civil Constitucional, Rio de Janeiro: Renovar, 2000.

. Temas de direito civil. Rio de Janeiro: Renovar, 1999.

. Temas de direito civil. Tomo /l. Rio de Janeiro: Renovar, 2006.

. A incorporação dos direitos fundamentais pelo ordenamento brasileiro: sua eficácia nas relações jurídicas privadas. Revista Jurídica, São Paulo, v. 341, p. 1127, março. 2006.

UBILLOS, Juan María Bilbao. ¿Em qué medida vinculan a los particulares a los derechos fundamentales?. Revista da Ajuris, Porto Alegre, n. 98, p. 333-367, junho. 2005.

VALE, André Rufino do. Constituição e direito privado: Algumas considerações sobre a eficácia dos direitos fundamentais nas relações privadas. Revista de Direito Público, Porto Alegre: Síntese, Brasília: Instituto Brasiliense de Direito Público, a. I, n. 6, p. 94-122, out.-dez. 2004.

Recebido para publicação 04/12/2007

Aceito para publicação 10/12/2007 